\title{
Direct Delivery of Intranasal Insulin to the Brain via Microemulsion as a Putative Treatment of CNS Functioning Disorders
}

\section{Shafir Botner ${ }^{1}$, Alon Friedman ${ }^{2}$ and Amnon C. Sintov ${ }^{1 *}$}

${ }^{1}$ Department of Biomedical Engineering, Faculty of Engineering Sciences, Ben Gurion University of the Negev, Beer Sheva 84105, Israel ${ }^{2}$ Department of Physiology and Neurobiology, Faculty of Health Sciences, Zlotowski Center for Neuroscience, Ben-Gurion University of the Negev, Beer-Sheva 84105, Israel

\begin{abstract}
Increasing the quantity of brain insulin has been demonstrated to play an important role in various neurological and pathological conditions. Controlling brain insulin levels might thus be important for cognitive functions and food intake. The goal of this study was to test the feasibility of increasing brain insulin levels by intranasal administration of insulin in microemulsion. Application of daily intranasal fluorescently labeled insulin (FITC-insulin) by water-in-oil microemulsion for 5 consecutive days to rats resulted in a significantly higher brain labeling compared with the aqueous solution as measured using quantitative image analysis of brain sections, that is, a two-fold higher average value than the average fluorescence level obtained after the same regimen of intranasal applications by an aqueous solution.

Interestingly, the fluorescence level in the brain after nasal applications of an aqueous solution was comparable with the intravenous administration of insulin, which may imply that the transport through the olfactory route after nasal application may compensate the poor systemic absorption of insulin solution by this route. The substantially high brain uptake of insulin, which has been shown following intranasal administration via microemulsion, is of great potential to targeting insulin to the brain in patients with neurological disorders, such as Alzheimer's disease.
\end{abstract}

Keywords: Intranasal drug delivery; Brain targeting; Insulin; Microemulsion; Blood-brain barrier; Alzheimer's disease

\section{Introduction}

It is now widely recognized that insulin possesses an important physiological role in the Central Nervous System (CNS), such as in memory and cognitive functions [1-8] as well as in control of food intake and body weight [9-14]. It has been shown by using positron emission tomography [15] that patients suffering from Alzheimer's Disease $(\mathrm{AD})$ displayed a progressive reduction in the cerebral metabolic rate for glucose, which correlated with clinical progression and actually predicted the transition from normal cognition to mild cognitive impairment and dementia. In a recent review, Zhao and Townsend [6] pointed out that type 2 diabetes mellitus and AD share common abnormalities, of which impaired glucose metabolism and elevated levels of advanced glycation end products contribute to the accumulation and aggregation of the amyloid-beta peptide, thus accelerate the disease progression. Other data have indicated that insulin is crucial to memory function and formation: (a) high densities of insulin receptors exist in the brain, including the hypothalamus and the hippocampus $[16,17]$; (b) reduced cerebrospinal fluid (CSF)-toplasma insulin ratios have been demonstrated in $\mathrm{AD}$ patients compared to healthy subjects $[18,19]$; and (c) direct intracerebroventricular administration or IV infusion of insulin while maintaining euglycemia improve memory ability in patients with $\mathrm{AD}$ probably by increasing brain insulin and/or overcoming insulin resistance $[1,2,18,20,21]$. Since treatment of $\mathrm{AD}$ with insulin was found to be beneficial, $\mathrm{AD}$ has been considered at least by one research group as type-3 diabetes [22]. In addition to its role in maintaining cognitive functions, insulin provides a negative feedback signal to hypothalamic nuclei controlling whole body energy and glucose homeostasis while balancing the amount of body fat [9]. Also, recent findings have shown that administration of insulin to the hypothalamus regulates core body temperature and thermogenesis in brown adipose tissue (factors which are dictating the energy balance) by direct inhibitory effects on warm-sensitive neurons [23]. It has been established that systemic insulin crosses the blood-brain barrier (BBB) to the brain by using an active, unidirectional, receptormediated transport system [24-27]. Indeed, insulin transporters can alter the rate of insulin transport into the CNS under a variety of circumstances. For example, elevation of peripheral plasma insulin levels increases the concentration of insulin in the CSF thus raises the signaling that modulates insulin-related functions [21]. In addition, insulin transport is likely to be faster in neonates than in adults [28], slower in Alzheimer's disease and faster in diabetes mellitus-induced animal models $[19,29]$. Obese, hyper-insulinemic Zucker rats exhibit a reduction in the number of BBB insulin receptors [30], which may account for the decrease in CSF insulin uptake in obesity $[10,31]$.

Increasing interest has been expressed in the potential of the nasal route in circumventing the (blood-brain barrier) BBB for the delivery of drugs, including insulin, into the CNS [32-35]. The olfactory region has been marked as a relatively open gate for direct transport from nose to brain $[32,35]$. Due to the unique anatomical organization of the olfactory nerves, a drug can circumvent BBB by (a) neuronal endocytosis followed by intracellular transport and axonal migration to the olfactory bulb with subsequent possible distribution of the drug into distant brain tissues, and (b) paracellular diffusion through the intercellular clefts in the olfactory epithelium and through the channels created between the ensheathing cells surrounding the olfactory axons in the lamina propria towards the CSF and the olfactory bulb $[32,36,37]$. Intranasal delivery to targeting drugs into the brain, or so

${ }^{*}$ Corresponding author: Amnon C. Sintov, Laboratory for Biopharmaceutics, E.D. Bergmann Campus, Ben Gurion University of the Negev, P.O. Box 653, Beer Sheva 84105, Israel, Tel: 9728647 2709; Fax. 9728647 2984; E-mail: asintov@bgu.ac.il

Received February 29, 2012; Accepted May 18, 2012; Published May 21, 2012

Citation: Botner S, Friedman A, Sintov AC (2012) Direct Delivery of Intranasal Insulin to the Brain via Microemulsion as a Putative Treatment of CNS Functioning Disorders. J Nanomed Nanotechol 3:136. doi:10.4172/2157-7439.1000136

Copyright: $\odot 2012$ Botner S, et al. This is an open-access article distributed under the terms of the Creative Commons Attribution License, which permits unrestricted use, distribution, and reproduction in any medium, provided the original author and source are credited. 
called the "nose-to-brain" route, might be efficient enough to achieve therapeutic effects in the CNS of neurological impaired humans by drugs which are not (or less) permeable the BBB [37]. In particular, it has been suggested that intranasal delivery of insulin may have therapeutic benefit for patients with $\mathrm{AD}$, i.e., facilitating cognition by increasing brain insulin signaling [7,38-42]. Nasal insulin, while delivered through the olfactory and trigeminal nerves, may bypass the $\mathrm{BBB}$ and its saturable transporters, resulting in increase of the CNS-toplasma insulin ratio.

Here, we report that increasing brain insulin levels may be feasible by using intranasal administration of fluorescently labeled insulin formulated within a water-in oil microemulsion. In our previous publication [43], we demonstrated an increased systemic absorption of intranasal insulin by using a new microemulsion system in a form of a spray. Although this system has been aimed for treatment of diabetic patients and apparently suffers from a disadvantage of whole body distribution, it has been hypothesized that if a significantly enhanced brain targeting of insulin is achieved by this special preparation, the systemic exposure could be easily compensated by both reduction in nasal dosage and focal localization to the olfactory region to obtain an effective treatment of cognitive impairments.

\section{Materials and Methods}

\section{Materials}

Fluorescein Isothiocyanate (FITC)-Insulin was purchased from Aldrich (Sigma-Aldrich Inc., St. Louis, MO). Glyceryl oleate was obtained from Uniqema, Bromborough Pool, The Wirral, UK. Labrasol was obtained from Gattefosse, France. Isopropyl palmitate (IPP) and propylene carbonate were purchased from Aldrich (SigmaAldrich Inc., St. Louis, MO). Acepromazine $(10 \mathrm{mg} / \mathrm{ml}$ acepromazine maleate solution) was used from PromAce Injectable, Fort DodgeAnimal Health (Iowa, USA). Isoflourane was purchased from Nicholas (Nicholas Piramal, India). O.C.T compound embedding medium (manufactured by Sakura Finetek, USA, Inc.) was purchased from a local distributor.

\section{Preparation of the microemulsion}

Microemulsion was prepared as previously described by our group [43]. Briefly, a FITC-Insulin $(5 \mathrm{mg} / \mathrm{ml})$ solution in water was mixed with labrasol and glyceryl oleate (surfactants), isopropyl palmitate (oil), and propylene carbonate (co-surfactant). The aqueous phase was $20 \%$ (by weight), the cosurfactant-surfactants $(\mathrm{CoS} / \mathrm{S})$ weight ratio was 1:5, and the surfactants' ratio was 1:3. The final microemulsion preparation contained $1 \mathrm{mg} / \mathrm{ml}(\mathrm{w} / \mathrm{v})$ FITC-insulin. The obtained monophasic formulations were formed after a short stirring at room temperature.

\section{Study design}

All animal procedures were performed in accordance with protocols reviewed and approved by the Institutional \& Use Committee, BenGurion University of the Negev, which complies with the Israeli Law of Human Care and Use of Laboratory Animals. Sprague Dawley rats (males, 200-250 g of body weight, Harlan, Jerusalem) were used. Rats were housed with a free access to food and water. A $12 \mathrm{~h}$ light $/ 12 \mathrm{~h}$ dark cycle was held to keep a normal circadian rhythm in the animals. In a first study, animals were separated into nine groups ( 3 to 5 rats each). The grouping was according to three criteria, type of formulation used (nasal aqueous solution vs. nasal microemulsion), the route of administration (intranasal vs. intravenous), and the dosage regimen (1, 2 or 3 times in $24 \mathrm{~h}$ ). In a following study, the intranasal administration of FITC-insulin via microemulsion was compared with intranasal administration of plain aqueous solution only, but in this study the dosage regimen was once-daily for 5 consecutive days. The two nasal formulations contained the same FITC-Insulin concentration, and the same liquid volume was applied. Animals had been sedated with isoflurane vapor just before $5 \mu \mathrm{l}$ of microemulsion (IN microemulsion group) or aqueous solution (IN solution group) were applied to each nostril using a pipette tip. The tip was positioned at the opening of the nostril while the animal was placed on its back, and formulation gradually released in accordance with the animal inspiration. For intravenous application (IV group), the animals were anaesthetized with ketamine, xylazine and acepromazine and $0.5 \mathrm{ml}$ of FITC-insulin solution (water for injection/FITC Insulin) was injected to the caudal vein of the tail. At the end-point of the experiment ( 24 hours or 5 days after applications had started), each animal was deeply anaesthetized with ketamine and xylazine and sacrificed. After decapitation, the skull was cut quickly and gently starting from the atlas, at the mid temporal line along the occipital, frontal and nasal regions. Afterwards the occipital, frontal and nasal (premaxilla) bones could be easily lifted up to expose the whole brain including the olfactory bulb. The brain was then carefully removed with the olfactory bulb and embedded in O.C.T solution. Each brain was embedded individually in the O.C.T compound solution, frozen immediately with liquid nitrogen and kept at $-20^{\circ} \mathrm{C}$ protected from light until processed for microscope visualization. All samples were protected from light during all experiment stages.

\section{Brain preparation for microscopy}

Brains were sectioned using a cryostat (CM 1950, Leica, $-21^{\circ} \mathrm{C}$, $9 \mu \mathrm{M}$ thick). The sectioning was performed in the coronal plane and slices were taken from the frontal lobes only starting from the tip of the olfactory bulb (Pathological Institute, Soroka University Medical Center). Images were taken using a fluorescence microscope (DM 4500B, Leica; EL 6000, Xcite light; I3 filter Cube, Leica), and a DFC $340 \mathrm{FX}$ digital camera (Leica, $66.5 \mathrm{~ms}$ exposure, Leica application suite v.3.7.0 software).

\section{Image processing}

Fluorescent intensity was measured from the acquired images using in-house Matlab script [44]: RGB channels were separated, and only the intensity in the green channel was calculated for each image. In purpose to reduce a background green level that may exist, the regions with higher intensity than the average were normalized by applying the average value that had been calculated for each image, denoted as "a", as the threshold level. This resulted in an image consisting of pixels with a higher intensity than the average. The average of these pixels, denoted as "b", was then calculated as followed:

$$
\begin{aligned}
& \mathrm{a}=\frac{\sum \text { green intensity pixels }}{\sum \text { pixels per picture }} \\
& \mathrm{b}=\frac{\sum_{a}^{\infty} \text { green intensity pixels }}{\sum_{a}^{\infty} \text { number of pixels }}
\end{aligned}
$$

\section{Statistical analysis}

All data are reported as mean \pm standard deviation, and the difference between the " $b$ " values obtained from the various groups of animals was analyzed. The unweighted means analysis of variance (ANOVA) test for the differences among group means was used and differences at a significance level $<0.05$ were considered significant. The normal distribution of data analyzed by the ANOVA procedure was ascertained using the Kolmogorov-Smirnov test. 


\section{Results and Discussion}

The microemulsion contained an inner aqueous phase with a mean globule size of approximately $2 \mathrm{~nm}$ in diameter $(2.26 \mathrm{~nm}$ after loading with insulin), as measured by dynamic light scattering. When FITClabeled insulin is loaded in the microemulsion at a concentration of 1 $\mathrm{mg} / \mathrm{ml}$, a self-quenching phenomenon associated with the fluorescent marker can be observed at this level (Figure 1, upper). As seen, the dark yellow color obtained in $1 \mathrm{mg} / \mathrm{ml}$ aqueous FITC-insulin solution almost entirely disappeared in microemulsion containing $20 \%$ aqueous FITC-insulin $(5 \mathrm{mg} / \mathrm{ml})$ nano-dispersed in the oily medium. A partial resumption of the yellow color (and apparently the fluorescence emission) occurred after two-fold dilution of the microemulsion with distilled water (Figure 1, bottom), indicating that either some encapsulated FITC-insulin was still remaining in the system or it was concentrated in the interfacial membrane of the inversed system.

Substantially higher uptake of FITC-insulin into the brain was noted with intranasal administration via microemulsion, compared with both intranasal administration of aqueous solution and intravenous administration at the same dose and dosage regimen. Figure 2 exemplifies the fluorescence emission in brain sections after intranasal administrations of insulin containing microemulsion and plain solution and after intravenous administration. A clear increase in fluorescence intensity was seen in photomicrographs of brain tissue obtained 24 hours after 1, 2 or 3 intranasal applications of microemulsion containing FITC-insulin, compared with the corresponding intranasal applications or intravenous injections of an aqueous solution. Table 1 summarizes the mean values of the fluorescence intensities and its distribution as calculated according to Matlab image processing using at least ten sample photographs taken under a fluorescence microscope from the various sections of each rat brain. The data showed that $24 \mathrm{~h}$ after a single intranasal administration of $10 \mu \mathrm{g}$ FITC-insulin per animal the mean fluorescence level was $86.3 \pm 36.1$ pdu with microemulsion and $51.4 \pm 13.2 \mathrm{pdu}$ with an aqueous solution. After IV administration of $10 \mu \mathrm{g}$ FITC-insulin, the mean level $(49.6 \pm 10.1$ pdu) was similar to the level obtained after nasal administration of an aqueous solution. Twenty four hours after 2 applications ( 0 and 12h) of $10 \mu \mathrm{g}$ FITC-insulin per animal, the mean fluorescence level was $138.5 \pm 80.6$ pdu with microemulsion administration and $48.7 \pm$ $5.5 \mathrm{pdu}$ with an aqueous solution, while after IV administration the mean level was $46.0 \pm 8.5 \mathrm{pdu}$. In both, once daily and twice daily, intranasal microemulsion resulted in a significantly higher uptake of FITC-insulin into the brain than nasal solution and IV administration (ANOVA, $\mathrm{p}<0.01$ ). Interestingly, the fluorescence level in the brain after nasal applications of aqueous solution was comparable with the intravenous administration, implying that while the intravenous route to the brain is mediated by insulin transporters of the BBB, intranasal insulin (having a poor systemic absorption from solution) apparently transports through the olfactory route. Importantly, 24 hours after 3 repeated intranasal applications $(0,8$, and $16 \mathrm{~h}$ ) of FITC-insulin (but not after one or two applications), the mean fluorescence level was 65.7 \pm 17.3 pdu with microemulsion administration, $36.4 \pm 4.5$ pdu with an aqueous solution, and $62.3 \pm 20.6$ pdu after IV administrations. Thus, while insulin was injected IV three times daily, brain uptake of the drug was significantly increased compared with once and twice daily injections. This increase in brain uptake was not observed when three intranasal doses of a microemulsion or aqueous solution of FITC-insulin were given, but rather a decrease in brain uptake was found. In this dose regimen (thrice daily), intranasal microemulsion was superior to intranasal solution of insulin, but was similar to IV

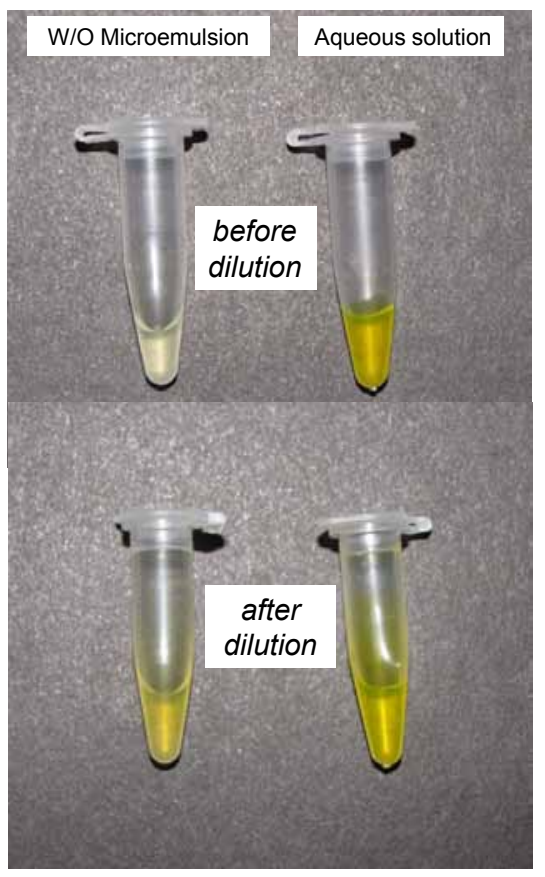

Figure 1: Self-quenching effect of FITC-insulin in microemulsion preparation A comparison is made between the color intensities of plain solution and microemulsion containing the fluorescently-labeled insulin at a concentration of $1 \mathrm{mg} / \mathrm{ml}$ (upper photograph). After dilution (x2) of both preparations with distilled water, a slight color difference still persists (lower photograph).

injection. While it is reasonable why higher systemic loading of insulin increases its delivery into the brain via pre-saturated BBB transporters, the decrease in the protein uptake by repeated doses through the nasal route is an interesting finding, suggesting that insulin uptake into the brain can be limited by increased rate of enzymatic degradation within the olfactory bulb (due to increase in protein concentration), as shown by Banks et al [45]. This phenomenon, however, may evidence the existence of different mechanisms of transport exhibited by the two routes, as the nose-to-brain delivery occurs by a direct transport mechanism bypassing the systemic circulation and the bloodbrain-barrier transport. Figure 3 shows the fluorescence emission obtained after once-daily applications of intranasal FITC-insulin for 5 consecutive days. Intranasal applications of microemulsion resulted in a strong fluorescence glowing and two-fold higher signal levels within brain sections compared with the aqueous solution $(109.4 \pm 45.5 \mathrm{pdu}$ vs. $51.6 \pm 7.1 \mathrm{pdu}$, Table 1$)$.

The mechanisms by which intranasal proteins are transported into the brain, particularly within the nano-vesicles of a microemulsion remained to be investigated. Two different pathways for drug uptake into the brain are claimed to exist: (a) the systemic pathway by which the drug is absorbed into the systemic circulation and subsequently reaches the brain by crossing the $\mathrm{BBB}$, and (b) the olfactory pathway (and the trigeminal route) by which the drug migrates to the CSF and brain tissue. Drugs transporting through the olfactory neurons (intracellular axonal transport) are thought to internalize within neurons by mechanisms of endocytosis or pinocytosis. They travel along axons and via the nerve bundle, transverse the cribriform plate reaching the olfactory bulb. Such transport of different materials (metals, macromolecules, viruses) along the axonal route has been shown earlier by several researchers [36, 46,47]. These studies also showed that drug transport along axons is extremely slow and can take 
Citation: Botner S, Friedman A, Sintov AC (2012) Direct Delivery of Intranasal Insulin to the Brain via Microemulsion as a Putative Treatment of CNS Functioning Disorders. J Nanomed Nanotechol 3:136. doi:10.4172/2157-7439.1000136
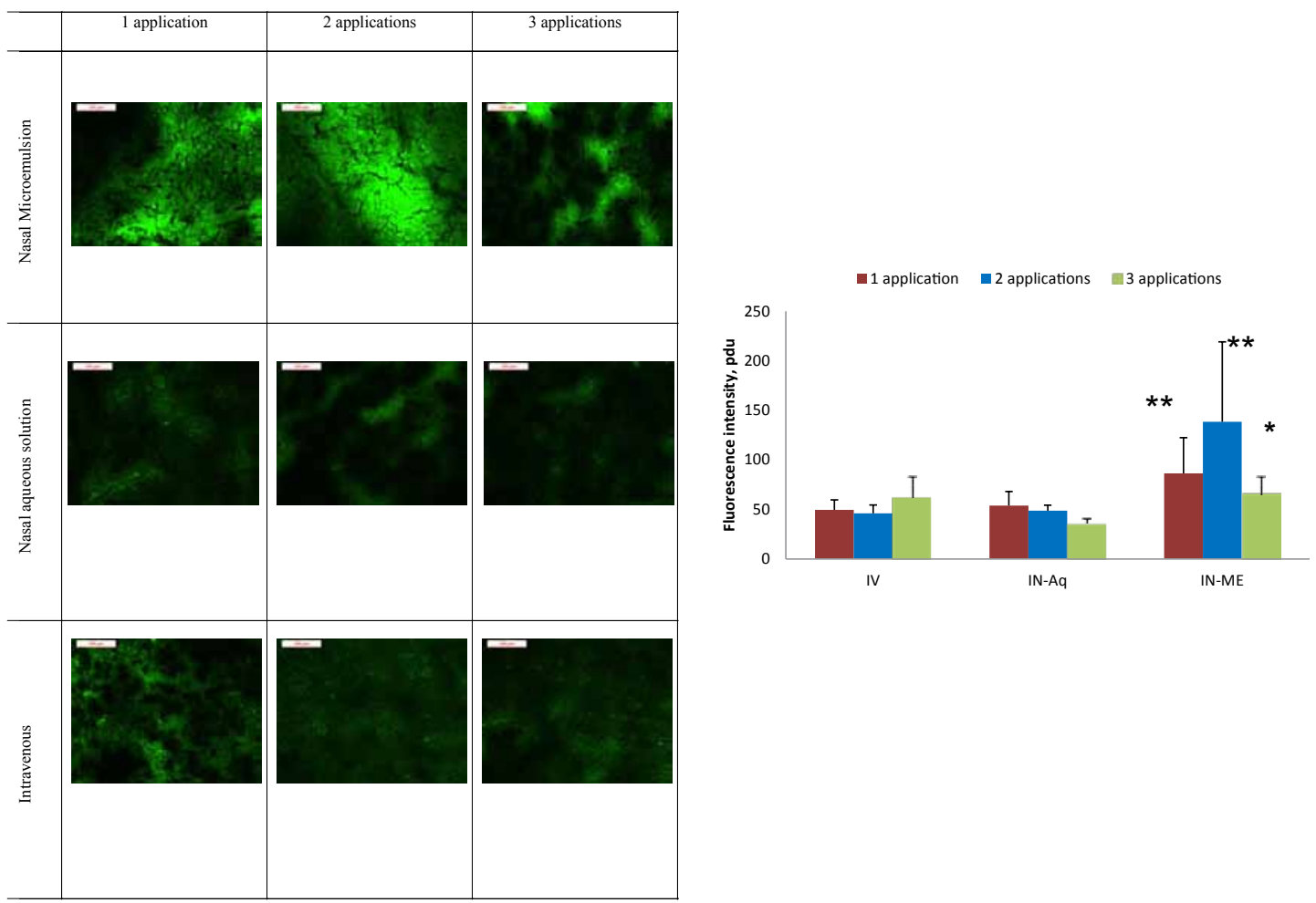

Figure 2: Comparison between the fluorescence emissions in brain cross-sections (about 15 slices) obtained after 24 hours following 1,2 and 3 administrations of intranasal FITC-insulin in aqueous solution or microemulsion to rats $(n=11)$. A comparison was also made with the corresponding systemic IV administrations of FITCinsulin solution $(n=3)$. All photographs were taken at the same magnification and light conditions. Also are shown the averaged fluorescence levels as processed by MATLAB software. Significant difference between intranasal microemulsion and both nasal aqueous solution and intravenous injections is denoted as ** and between intranasal microemulsion and nasal aqueous solution only is denoted as * (see also Table 1).

\begin{tabular}{|c|c|c|c|}
\hline FITC-insulin treatment $(40-50 \mu \mathrm{g} / \mathrm{kg})$ & Route of administration & Dose regimen & Averaged fluorescence level (pdu*) \\
\hline Microemulsion & Intranasal & $1 \times 1 d$ & $86.3 \pm 36.1(n=13)^{s 1, s 2}$ \\
\hline Aqueous solution & Intranasal & $1 \times 1 d$ & $51.4 \pm 13.2(n=13)$ \\
\hline Aqueous solution & IV & $1 \times 1 d$ & 49. $6 \pm 10.1(n=14)$ \\
\hline Microemulsion & Intranasal & $2 \times 1 d$ & $138.5 \pm 80.6(n=10)^{s 1, s 2}$ \\
\hline Aqueous solution & Intranasal & $2 \times 1 d$ & $48.7 \pm 5.5(n=14)$ \\
\hline Aqueous solution & IV & $2 \times 1 d$ & $46.0 \pm 8.5(n=11)$ \\
\hline Microemulsion & Intranasal & $3 \times 1 d$ & $65.7 \pm 17.3(n=13)^{s 1}$ \\
\hline Aqueous solution & Intranasal & $3 \times 1 d$ & $36.4 \pm 4.5(n=15)^{\mathrm{S2}}$ \\
\hline Aqueous solution & IV & $3 \times 1 d$ & $62.3 \pm 20.6(n=13)^{s 1}$ \\
\hline Microemulsion & Intranasal & $1 \times 1 d$ for $5 d$ & $109.4 \pm 45.5(n=15)^{s 1}$ \\
\hline Aqueous solution & Intranasal & $1 \times 1 d$ for $5 d$ & $51.6 \pm 7.1(n=31)$ \\
\hline
\end{tabular}

*pdu is the abbreviation for 'procedure defined unit'

Table 1: Determination of fluorescence levels in brain tissue slices using MATLAB image processing. Statistically significant difference (ANOVA, $p<0.01$ ) compared with data obtained after administrations at the same dose regimen of nasal aqueous solution ${ }^{\mathrm{S1}}$ and IV aqueous solution ${ }^{\mathrm{S2}}$.

$1 \times 1 \mathrm{~d}=24$ hours after 1 application:

$2 \times 1 \mathrm{~d}=24$ hours after 2 applications at $\mathrm{t}=0$ and $12 \mathrm{~h}$;

$3 \times 1 \mathrm{~d}=24$ hours after 3 applications at $\mathrm{t}=0,8 \mathrm{~h}$, and $16 \mathrm{~h}$;

$1 \times 1 d$ for $5 d=$ at day 5 after 5 daily applications.

up to 24 hours before the drug reaches the CNS. Additional pathway (also so-called a direct entry into the brain) appears to be much faster, with drugs appearing in the CSF and in the brain in a few minutes after nasal application. By this latter route, the drug seems to enter the perineural space which surrounding the olfactory nerves, either through loosely adherent perineural epithelium surrounding the axon or through the epithelial cell junctions if the perineural epithelium is closely adherent to the axon. It has been shown in a rat model that large molecular weight drugs, such as protein nerve growth factor (37 $\mathrm{kDa})$ [48], insulin $(5.7 \mathrm{kDa})$ and Vasoactive Intestinal Peptide (VIP) $(3.5 \mathrm{kDa})[21,49]$ can be transported rapidly into the CSF by this route.

\section{Conclusions}

Our findings reveal that a significant quantity of fluorescentlylabeled insulin can be effectively delivered to the brain by intranasal administration of formulated microemulsion. The study also 


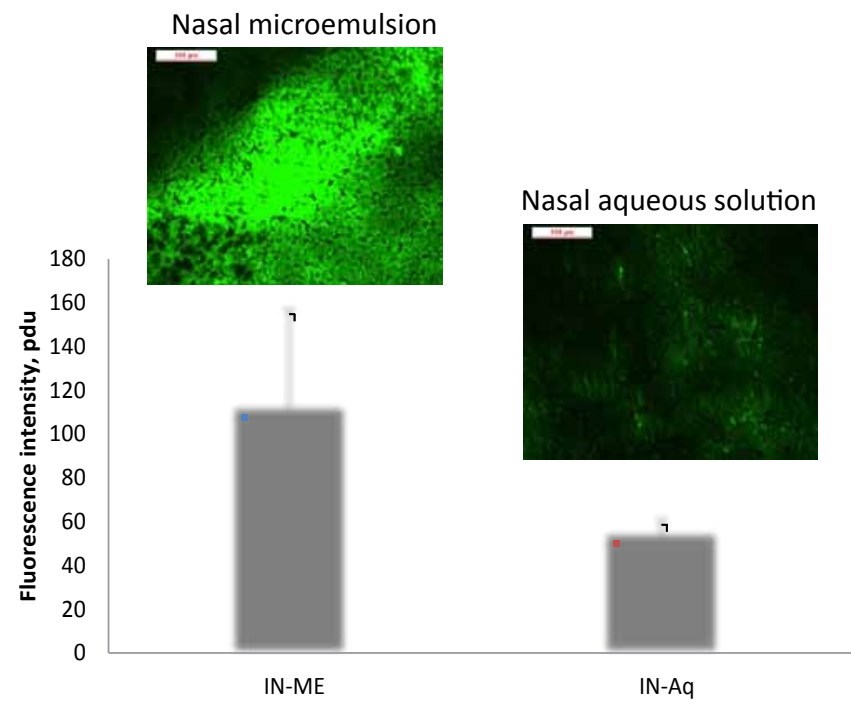

Figure 3: Photographs of rat brain tissue of animals treated intranasally with FITC-insulin once-daily for five days ( 5 consecutive applications) ( $n=8$ rats) The difference in the fluorescnce glowing is obtained due to the different formulations, microemulsion vs. aqueous solution. The photographs were taken under the fluorescence microscope at the same magnification and light conditions.

demonstrated a larger extent of nose-to-brain transport compared with insulin aqueous solution, and a clear preference of intranasal microemulsion over intravenous administration on brain uptake. In view of these results, it is suggested that intranasal delivery of lowdose insulin by an optimized formulation, which would be targeted to the olfactory region, might be a potential treatment in conditions like Alzheimer's disease and obesity. It has also been conceivable to increase the microemulsion viscosity to prevent mixing with foreign compounds in the nasal environment, thus avoiding their unintentional brain entry. Further work is still remaining to be done using animal models which mimic the disease states to test whether the same pharmacokinetic parameters are held. In addition, benefits to risk ratio should be evaluated through further animal studies followed by human trials to establish its suitability in clinical practice.

\section{Acknowledgments}

The work was performed in partial fulfillment of the requirements for the Ph.D. degree of S. Botner. The study was sponsored and supported in part by NanoDerma Ltd. (Ra'anana, Israel). The authors would like to acknowledge the professional assistance provided by Prof. Hagit Cohen at the Mental Health CenterBeer Sheva, Dr. Yoash Hassidim of The Zlotowski Center for Neuroscience; Mr. Gil Rodnitzky, and Mr. Igor Krymberk at the Laboratory of Biopharmaceutics, E.D. Bergmann campus, Ben-Gurion University of the Negev, Beer Sheva, Israel.

\section{References}

1. Park CR, Seeley RJ, Craft S, Woods SC (2000) Intracerebroventricular insulin enhances memory in a passive-avoidance task. Physiol Behav 68: 509-514

2. Kern W, Peters A, Fruehwald-Schultes B, Deininger E, Born J, et al (2001) Improving influence of insulin on cognitive functions in humans. Neuroendocrinology $74: 270-280$.

3. Benedict C, Hallschmid M, Hatke A, Schultes B, Fehm HL, et al. (2004) Intranasal insulin improves memory in humans. Psychoneuroendocrinology 29: 1326-1334.

4. Benedict C, Hallschmid M, Schultes B, Born J, Kern W (2007) Intranasal insulin to improve memory function in humans. Neuroendocrinology $86: 136-142$.
5. Benedict C, Hallschmid M, Schmitz K, Schultes B, Ratter F, et al. (2007) Intranasal insulin improves memory in humans: superiority of insulin aspart Neuropsychopharmacology 32: 239-243.

6. Zhao WQ, Townsend $M$ (2009) Insulin resistance and amyloidogenesis as common molecular foundation for type 2 diabetes and Alzheimer's disease. Biochim Biophys Acta 1792: 482-496.

7. Reger MA, Watson GS, Frey WH 2nd, Baker LD, Cholerton B, et al. (2006) Effects of intranasal insulin on cognition in memory-impaired older adults: modulation by APOE genotype. Neurobiol Aging 27: 451-458.

8. Biessels GJ, Staekenborg S, Brunner E, Brayne C, Scheltens P (2006)Risk of dementia in diabetes mellitus: a systematic review. Lancet Neurol 5: 64-74.

9. Hallschmid M, Schultes B (2009) Central nervous insulin resistance: a promising target in the treatment of metabolic and cognitive disorders? Diabetologia 52 : 2264-2269.

10. Kern W, Benedict C, Schultes B, Plohr F, Moser A, et al. (2006) Low cerebrospinal fluid insulin levels in obese humans. Diabetologia 49: 2790-2792.

11. Hallschmid M, Benedict C, Schultes B, Fehm HL, Born J, et al. (2004) Intranasal insulin reduces body fat in men but not in women. Diabetes 53: 3024-3029.

12. Mei J, Cheng Y, Erlanson-Albertsson C (1993) Enterostatin--its ability to inhibit insulin secretion and to decrease high-fat food intake. Int J Obes Relat Metab Disord 17: 701-704.

13. Schwartz MW, Boyko EJ, Kahn SE, Ravussin E, Bogardus C (1995) Reduced insulin secretion: an independent predictor of body weight gain. J Clin Endocrinol Metab 80: 1571-1576.

14. Kaiyala KJ, Prigeon RL, Kahn SE, Woods SC, Schwartz MW (2000) Obesity induced by a high-fat diet is associated with reduced brain insulin transport in dogs. Diabetes 49: 1525-1533.

15. Mosconi L, Mistur R, Switalski R, Tsui WH, Glodzik L, et al. (2009) FDG-PET changes in brain glucose metabolism from normal cognition to pathologically verified Alzheimer's disease. Eur J Nucl Med Mol Imaging 36: 811-822.

16. Havrankova J, Roth J, Brownstein M (1978) Insulin receptors are widely distributed in the central nervous system of the rat. Nature 272: 827-829.

17. Adamo M, Raizada MK, LeRoith D (1989) Insulin and insulin-like growth factor receptors in the nervous system. Mol Neurobiol 3: 71-100.

18. Craft S, Newcomer J, Kanne S, Degogo-Jack S, Cryer P, Sheline $Y$, et al. (1996) Memory improvement following induced hyperinsulinemia in Alzheimer's disease. Neurobiol Aging 17: 123-130.

19. Craft S, Peskind E Schwartz MW, Schellenberg GD, Raskind M, Porte D, J (1998) Cerebrospinal fluid and plasma insulin levels in Alzheimer's disease: relationship to severity of dementia and apolipoprotein E genotype. Neurology 50: $164-168$

20. Craft S, Asthana S, Cook DG, Baker LD, Cherrier M, et al. (2003) Insulin dose-response effects on memory and plasma myloid precursor protein in Alzheimer's disease: interactions with apolipoprotein $E$ genotype. Psychoneuroendocrinology 28: 809-822.

21. Wallum BJ, Taborsky GJ Jr, Porte D Jr, Figlewicz DP, Jacobson L, et al. (1987) Cerebrospinal fluid insulin levels increase during intravenous insulin infusions in man. J Clin Endocrinol Metab 64: 190-194.

22. Steen E, Terry BM, Rivera EJ, Cannon JL, Neely TR, et al. (2005) Impaired insulin and insulin-like growth factor expression and signaling mechanisms in Alzheimer's disease - Is this type 3 diabetes? J Alzheimers Dis 7: 63-80.

23. Sanchez-Alavez M, Tabarean IV, Osborn O, Mitsukawa K, Schaefer J, et al. (2010) Insulin causes hyperthermia by direct inhibition of warm-sensitive neurons. Diabetes 59: 43-50.

24. Schwartz MW, Bergman RN, Kahn SE, Taborsky GJ Jr, Fisher LD, et al. (1991) Evidence for entry of plasma insulin into cerebrospinal fluid through an intermediate compartment in dogs. Quantitative aspects and implications for transport. J Clin Invest 88: 1272-1281.

25. Baskin DG, Figlewicz DP, Woods SC, Porte D Jr, Dorsa DM (1987) Insulin in the brain. Ann Rev Physiol 49: 335-347.

26. Banks WA, Jaspan JB, Huang W, Kastin AJ (1997) Transport of insulin across the blood-brain barrier: saturability at euglicemic doses of insulin. Peptides 18 1423-1429. 
Citation: Botner S, Friedman A, Sintov AC (2012) Direct Delivery of Intranasal Insulin to the Brain via Microemulsion as a Putative Treatment of CNS Functioning Disorders. J Nanomed Nanotechol 3:136. doi:10.4172/2157-7439.1000136

Page 6 of 6

27. Baura GD, Foster DM, Porte D Jr, Kahn SE, Bergman RN, et al. (1993) Saturable transport of insulin from plasma into the central nervous system of dogs in vivo. A mechanism for regulated insulin delivery to the brain. $\mathrm{J}$ Clin Invest 92: 1824-1830.

28. Frank HJL, Jankovic-Vokes T, Partridge WM, Morris WL (1985) Enhanced insulin binding to blood-brain barrier in vivo and to brain microvessels in vitro in newborn rabbits. Diabetes 34: 728-33.

29. Banks WA, Jaspan JB, Kastin AJ (1997) Effect of diabetes mellitus on the permeability of the blood-brain barrier to insulin. Peptides 18: 1577-1584.

30. Schwartz MW, Figlewicz DF, Kahn SE, Baskin DG, Greenwood MR, et al. (1990) Insulin binding to brain capillaries is reduced in genetically obese, hyperinsulinemic Zucker rats. Peptides 11: 467-472.

31. Hallschmid M, Benedict C, Schultes B, Born J, Kern W (2008) Obese men respond to cognitive but not to catabolic brain insulin signaling. Int $\mathrm{J}$ Obes 32 : 275-282.

32. Illum $L$ (2000) Transport of drugs from the nasal cavity to the central nervous system. Eur J Pharm Sci 11: 1-18.

33. Illum L (2003) Nasal drug delivery-possibilities, problems and solutions. J Control Rel 87: 187-198.

34. Illum L (2004) Is nose-to-brain transport of drugs in man a reality? J Pharm Pharmacol 56: 3-17.

35. Dhuria SV, Hanson LR, Frey WH II (2010) Intranasal delivery to the centra nervous system: mehanisms and experimental considerations. J Pharm Sci 99: 1654-1673

36. Thorne RG, Emory CR, Ala TA, Frey WH $2^{\text {nd }}$ (1995) Quantitative analysis of the olfactory pathway for drug delivery to the brain. Brain Res 692: 278-282.

37. Hanson LR, Frey WH $2^{\text {nd }}(2008)$ Intranasal delivery bypasses the blood-brain barrier to target therapeutic agents to the central nervous system and treat neurodegenerative disease. BMC Neurosci 9: S5.

38. Reger MA, Watson GS, Green PS, Wilkinson CW, Baker LD, et al. (2008) Intranasal insulin improves cognition and modulates beta-amyloid in early $A D$. Neurology 70: 440-448.
39. Reger MA, Watson GS, Green PS, Baker LD, Cholerton B, et al. (2008) Intranasal insulin administration dose-dependently modulates verbal memory and plasma beta-amyloid in memory-impaired older adults. J Alzheimers Dis 13: 323-331.

40. Francis GJ, Martinez JA, Liu WQ, Xu K, Ayer A, et al. (2008) Intranasal insulin prevents cognitive decline, cerebral atrophy and white matter changes in murine type I diabetic encephalopathy. Brain 131: 3311-3334.

41. Laron Z (2009) Insulin and the brain. Arch Physiol Biochem 115: 112-116.

42. Benedict C, Frey WH 2nd, Schioth HB, Schultes B, Born J, et al. (2011) Intranasal insulin as a therapeutic option in the treatment of cognitive impairments. Exp Gerontol 46: 112-115.

43. Sintov AC, Levy HV, Botner S (2010) Systemic delivery of insulin via the nasal route using a new microemulsion system: In vitro and in vivo studies. J Control Release 148: 168-176.

44. Tomkins O, Friedman O, Ivens S, Reiffurth C, Major S, et al. (2007) Bloodbrain barrier disruption results in delayed functional and structural alterations in the rat neocortex. Neurobiol Dis 25: 367-377.

45. Banks WA, Kastin AJ, Pan W (1999) Uptake and degradation of blood-borne insulin by the olfactory bulb. Peptides 20: 373-378.

46. Evans J, Hastings L (1992) Accumulation of Cd(II) in the CNS depending on the route of administration: intraperitoneal, intratracheal, or intranasal. Fundam Appl Toxicol 19: 275-278.

47. Perlman S, Sun N, Barnett EM (1995) Spread of MHV-JHM from nasal cavity to white matter of spinal cord. Transneuronal movement and involvement of astrocytes. Adv Exp Med Biol 380: 73-78.

48. Thorne RG, Frey WH $2^{\text {nd }}$ (2001) Delivery of neurotrophic factors to the central nervous system: pharmacokinetic considerations. Clin Pharmacokinet 40: 907 946

49. Gozes I, Bardea A, Reshef A, Zamostiano R, Zhukovsky S, et al. (1996) Neuroprotective strategy for Alzheimer disease: intranasal administration of a fatty neuropeptide. Proc Natl Acad Sci USA 93: 427-432. 